\title{
Mitral valve repair in children with rheumatic heart disease
}

\author{
Sachin Talwar, MCh \\ Manithara Raman Rajesh, MS \\ Anandaraja Subramanian, DM \\ Anita Saxena, DM \\ Arkalgud Sampath Kumar, MCh
}

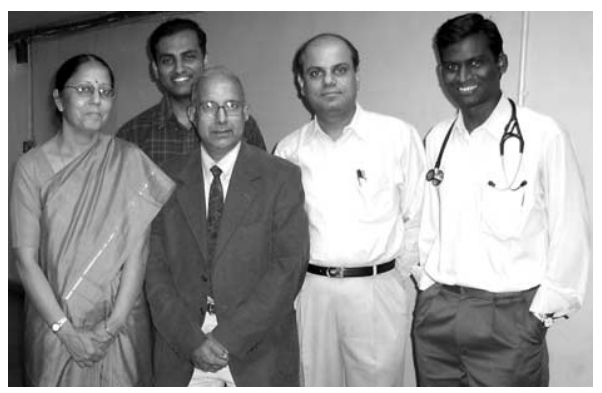

Saxena, Rajesh, Kumar, Talwar, Subramanian (left to right)
Objective: The purpose of this study was to assess the long-term results of mitral valve repair in children with chronic rheumatic heart disease.

Methods: From January 1988 through December 2003, 278 children (153 male children) underwent mitral valve repair. Mean age was $11.7 \pm 2.9$ years (range, 2-15 years). One hundred seventy-three children (62\%) were in the New York Heart Association functional class III or IV. Congestive heart failure was present in $24(8.6 \%)$. Reparative procedures included posterior collar annuloplasty $(\mathrm{n}=242)$, commissurotomy $(\mathrm{n}=187)$, cusp-level chordal shortening $(\mathrm{n}=94)$, cusp thinning $(n=71)$, cleft suture $(n=65)$, and cusp excision or plication $(n=10)$. Associated procedures included atrial septal defect closure $(n=22)$, aortic valve repair/ replacement $(\mathrm{n}=13)$, and tricuspid valve repair $(\mathrm{n}=3)$.
From the Cardiothoracic Centre, All India Institute of Medical Sciences, New Delhi, India.

Received for publication Aug 25, 2004; revisions received Nov 1, 2004; accepted for publication Nov 9, 2004.

Address for reprints: A. Sampath Kumar, MCh, Professor, Department of Cardiothoracic \& Vascular Surgery, Cardiothoracic Centre, All India Institute of Medical Sciences, Ansari Nagar, New Delhi-110 029, India (E-mail: asampath_kumar@hotmail. com).

J Thorac Cardiovasc Surg 2005;129:875-9 $0022-5223 / \$ 30.00$

Copyright () 2005 by The American Association for Thoracic Surgery

doi:10.1016/j.jtcvs.2004.11.006
Results: Early mortality was $2.2 \%$ (6 patients). Preoperative left ventricular dysfunction was associated with greater mortality. Median follow-up was 56.5 months (mean, 58.9. \pm 32.3 months; range, 5 to 180 months). One hundred seventy-seven survivors $(65 \%)$ had no or trivial mitral regurgitation. Sixteen patients $(6 \%)$ required reoperation for valve dysfunction. There were 7 late deaths (2.6\%). Actuarial, reoperation-free, and event-free survivals at a median follow-up of 56.5 months were $95.2 \% \pm 1.5 \%, 91.6 \% \pm 2.2 \%$, and $55.9 \% \pm 3.5 \%$, respectively; at 15 years, they were $95.2 \% \pm 1.5 \%, 85.9 \% \pm 5.9 \%$, and $46.7 \% \pm 4.7 \%$, respectively.

Conclusion: Mitral valve repair in children with chronic rheumatic heart disease is feasible and provides acceptable long-term results.

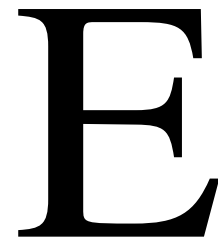

xperience with mitral valve repair in the rheumatic population is limited. ${ }^{1-6}$ Major hindrances to the less-frequent repairs in this population have been the unpredictability of long-term results and, more important, the complexity of the disease process, which make In 1995, we reported our initial experience with mitral valve reconstruction in 125 children operated on between 1988 and $1994 .{ }^{8}$ We now present detailed results with long-term follow-up.

\section{Patients and Methods}

From January 1988 through December 2003, 1022 patients underwent mitral valve reconstruction at our institution. We studied $278(27.2 \%)$ of these patients who were 15 years of age or younger. Of these 278 patients, $153(55 \%)$ were male. The mean age at surgery was $11.7 \pm 2.9$ years (range, 2-15 years). All patients had evidence of rheumatic heart disease. Pure mitral regurgitation (MR) was present in 123 (44\%) patients, and combined mitral stenosis (MS) and MR was present in $155(56 \%)$ patients. Atrial fibrillation (AF) was present 
in 143 patients $(51.4 \%)$. The predominant presenting symptom was dyspnea on exertion. One hundred seventy-three patients (62\%) were in New York Heart Association (NYHA) functional class III or IV. Congestive heart failure (CHF) was present in 24 $(8.6 \%)$ patients.

Preoperative transthoracic echocardiography was performed in all patients. Cardiac catheterization and cineangiography were performed on suspicion of associated aortic valve disease. MR was graded by Doppler echocardiography or angiography or by both according to previously published criteria. ${ }^{9,10}$ After January 1994, intraoperative transesophageal echocardiography was performed with a Hewlett- Packard Sonos 1500, 2500, or 5500 ultrasonography system. (Hewlett-Packard Co, Andover, Mass). Echocardiographic assessment included the annulus, leaflet thickness and mobility, commissural and chordal fusion, presence of calcification, regurgitant jet, thickness of the chordae tendineae, and the presence of clots in the left atrium or the left atrial appendage. Other valves were also assessed in a systematic fashion.

\section{Surgical Technique}

Surgical approach was via a median sternotomy $(\mathrm{n}=219)$ or, in female patients, a right anterolateral thoracotomy $(n=59)$ purely for cosmetic reasons. Aorto-bicaval cannulation was used in all patients. Before 1996 , moderately hypothermic $\left(32^{\circ} \mathrm{C}\right)$ cardiopulmonary bypass (CPB) was used. Since 1996, normothermic perfusion has been used in all patients. Antegrade cold blood cardioplegia and topical ice slush were used for myocardial production. The mitral valve was exposed through a standard incision in the left atrial wall behind the interatrial groove. In patients with an associated atrial septal defect (ASD), the approach was through the right atrium. After careful evaluation of the mitral valve, a variety of reparative procedures developed by us and described in detail in our previous publications ${ }^{5,8,11-13}$ was used. The procedures included posterior collar annuloplasty ${ }^{11}(n=242)$, commissurotomy ( $\mathrm{n}=187)$, cusp-level chordal shortening $(\mathrm{n}=94)$, cusp thinning $(n=71)$, cleft suture $(n=65)$, cusp excision or plication $(n=10)$, decalcification $(n=3)$, and chordal transfer $(n=3)$. No procedure was performed for correction of AF.

Associated procedures included atrial septal defect closure in 22 patients, aortic valve repair in 8 , aortic valve replacement in 5 , and tricuspid valve repair in 3 . At the completion of repair, mitral valve competence was tested by using a bulb syringe to inject cold saline into the left ventricular cavity with the aortic root vent open, and coaptation of leaflets was observed. Since 1994, transesophageal echocardiography has been used for assessment of repairs.

\section{Follow-up}

Transthoracic echocardiography was carried out in all patients before discharge from the hospital and repeated at 6 monthly intervals. Before 1998, all patients undergoing posterior collar annuloplasty were prescribed acenocoumarin for 6 weeks and dipyridamole for 6 months. Since April 1998, this practice has been discontinued. All patients were seen in the outpatient clinic at our hospital. The results of their clinical status and echocardiograms between January 2004 and July 2004 were recorded and are reported in this study.

\section{Statistical Analysis}

Data were analyzed with the SPSS 10.0 for Windows software package (SPSS Inc, Chicago Ill). Mean, median, and standard deviation were calculated for continuous variables. Univariate analysis was performed with the $\chi^{2}$ and Fisher exact tests. Actuarial estimates were calculated and compared by using the KaplanMeier analysis with Mantel-Cox log-rank tests. MR was considered to be significant if it was moderate or severe. Factors analyzed as predictors of early and late mortality and of development of significant MR included age, sex, type of lesion (MR or mixed), preoperative NYHA class, preoperative $\mathrm{CHF}$, presence of $\mathrm{AF}$, valve pathology (cusp prolapse, annular dilatation, chordal elongation, chordal rupture, calcification of valve leaflets), left ventricular dysfunction (ejection fraction $<50 \%, \mathrm{n}=24$ ), associated aortic and tricuspid valve disease, CPB and aortic crossclamp time, and various reparative techniques. All factors were subjected to multiple logistic regression analysis to determine the independent predictors of early mortality. The Cox proportional hazards model was used to determine the prognostic factors for significant MR.

\section{Results}

\section{Early Mortality}

All patients survived the operation. Mean aortic crossclamp time was 37.2 \pm 12.8 minutes (range, 23-66 minutes), and the mean CPB time was $47.6 \pm 11.9$ minutes (range, 36-83 minutes) for patients who underwent mitral valve repair alone. Fifteen patients (5.4\%) required inotropic support. Median duration of mechanical ventilation was 18 hours (range, 9-68 hours). Mean hospital stay was $5.8 \pm 1.7$ days (range, 4-29 days). There were 6 early deaths (2.2\%), which were encountered in the first 125 patients and reported by us earlier. ${ }^{8}$ Of these deaths, 5 were due to persistent low cardiac output caused by severe left ventricular dysfunction, and 1was due to cerebral infarction. No in-hospital deaths occurred in the last 153 consecutive patients.

\section{Late Outcome}

Follow-up was $98 \%$ complete $(\mathrm{n}=266)$ and ranged from 5 to 180 months (mean, $58.9 \pm 33.3$ months; median, 56.5 months). Total follow-up was 1335 patient-years. Among survivors, $19(7 \%)$ were followed up for 15 or more years, $25(9 \%)$, for 10 or more years, $116(43 \%)$, for more than 5 years, and $210(77 \%)$, for more than 3 years. We followed standard published guidelines ${ }^{14}$ in reporting freedom from valve-related events.

Thromboembolic complications. Four patients (1.5\%) had a thromboembolic complication ( 0.3 events per 100 patient-years) in the late postoperative period at a mean follow-up of $24 \pm 24.4$ months (range, 3-56 months). One of these patients died 3 months after surgery; the rest recovered uneventfully. Of the 4 patients, 3 had persistent AF.

Hemolysis. Sixteen patients had significant hemolysis (1.2 events per 100 patient-years) Nine of these had significant MR: two underwent MVR, 2 died without undergoing 
reoperation, and 5 are awaiting reoperation. Of the remaining 7 patients, 2 were lost to follow-up, and hemolysis gradually subsided in the other 5 .

Infective endocarditis. One patient had subacute bacterial endocarditis. He was treated conservatively and is well 32 months after initial surgery.

Reoperation. Sixteen patients underwent reoperation for severe valve dysfunction (1.2 events per 100 patient-years) after a mean period of $39.13 \pm 31.2$ months (range, 3-132 months). Freedom from reoperation was $91.6 \% \pm 2.2 \%$ at 56.5 months and $85.9 \% \pm 5.9 \%$ at 15 years (Figure 1). One patient underwent repeat mitral valve repair within 3 months due to dehiscence of the annuloplasty ring. Another patient underwent mitral valve replacement (MVR) with a cryopreserved mitral homograft 18 months after initial surgery; however, 24 months after MVR, he continued to have recurrent attacks of rheumatic fever with severe aortic regurgitation and MR for which he underwent prosthetic double-valve replacement. Of the other 14 patients, 2 underwent repeat mitral valve repair, and the rest underwent MVR. Two of the latter died postoperatively of low cardiac output.

Apart from the patient in whom dehiscence of the annuloplasty felt developed, the remaining patients had evidence of progression of the disease, with new thickening of the cusps and subvalvular fusion. Twelve of these patients had mixed MR and MS as the initial lesion.

Valve function. Of the 272 survivors, 177 (65\%) had no or trivial to mild MR at last follow-up. The remaining 95 patients $(35 \%)$ had significant MR after a median period of 34 months (mean, $35.6 \pm 34.5$ months), which was moderate in $52(19.1 \%)$ and severe in 43 patients $(15.9 \%)$. Fourteen patients with severe MR underwent reoperation; 3 died as a result of persistent CHF. Freedom from development of significant MR was $55.9 \% \pm 3.5 \%$ at a median of 56.5 months and $46.7 \% \pm 4.7 \%$ at 15 years. Multivariate analysis of risk factors for significant MR showed a high probability in patients with mixed (regurgitant and stenotic) lesions (hazard ratio, 1.72; 95\% confidence interval, 1.25$2.5 ; P=.006)$ and in patients with significant left ventricular dysfunction (hazard ratio, 4.9; 95\% confidence interval, 2.65-9.2; $P<.005$.)

Severe MS developed in 3 patients: two underwent reoperation, and 1 was lost to follow-up.

Functional class. One hundred seventy-seven patients with insignificant MR are in NYHA class I. Of the 52 patients with moderate MR, 46 are free of symptoms, 4 are in NYHA class II-III due to development of aortic valve disease, and 2 are in NYHA class III due to left ventricular dysfunction. Of the 43 patients with severe MR, 19 were in NYHA class III or IV: fourteen of the latter underwent reoperation, and 5 died due to persistent CHF. The remaining 24 patients are in either NYHA class I or II. Of the 3

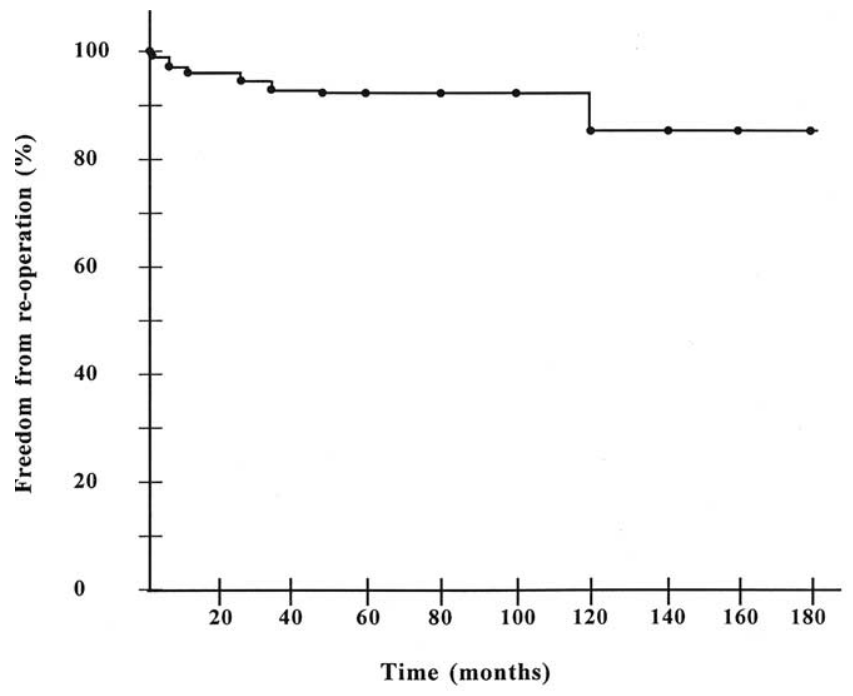

Figure 1. Freedom from reoperation (Kaplan-Meier) in children after mitral valve repair.

\begin{tabular}{lcccccc}
\hline Time interval (mo) & $\mathbf{0}$ & $\mathbf{1 2}$ & $\mathbf{3 6}$ & $\mathbf{6 0}$ & $\mathbf{1 2 0}$ & $\mathbf{1 8 0}$ \\
\hline Patients at risk & 272 & 202 & 156 & 110 & 25 & 19 \\
$\begin{array}{l}\text { Freedom from } \\
\quad \text { reoperation (\%) }\end{array}$ & 100 & 96.7 & 92.7 & 91.7 & 85.9 & 85.9 \\
\begin{tabular}{l} 
Standard error \\
\hline
\end{tabular} & 0 & 1.2 & 1.9 & 2.1 & 5.9 & 5.9 \\
\hline
\end{tabular}

patients with severe MS, 2 were in NYHA class IV and underwent reoperation, and 1 was lost to follow-up. A total of 160 patients $(60 \%)$ are in normal sinus rhythm.

Late deaths and survival. There were 7 late deaths (2.6\%) after a median period of 18 months (mean, $31 \pm$ 41.2 months; range, 2.2 to 118 months). Two patients died at reoperation: 3 due to persistent $\mathrm{CHF}$ while awaiting reoperation, 1 due to cerebrovascular accident, and 1 due to acute viral hepatitis.

Actuarial survival in the 278 patients was $95.2 \% \pm 1.5 \%$ at 56.5 months and was similar at 15 years. In patients with left ventricular dysfunction, the survival at 56.5 months was $63.8 \% \pm 14.9 \%$ compared with $99 \% \pm 0.1 \%$ in patients with normal left ventricular function. Left ventricular function was an independent predictor of late death $(P=.017)$. Event-free survival in survivors was $55.9 \% \pm 3.5 \%$ at 56.5 months and $46.7 \% \pm 4.7 \%$ at 15 years (Figure 2).

\section{Discussion}

Two thirds of patients with rheumatic heart disease in developing countries are of school age. ${ }^{15}$ Because of recurrent rheumatic fever, a large proportion of these patients have chronic rheumatic mitral valve disease requiring surgery. Valve replacement is not the best option in these patients because of (1) higher mortality compared with adults; (2) small size of the implanted valve due to smaller 


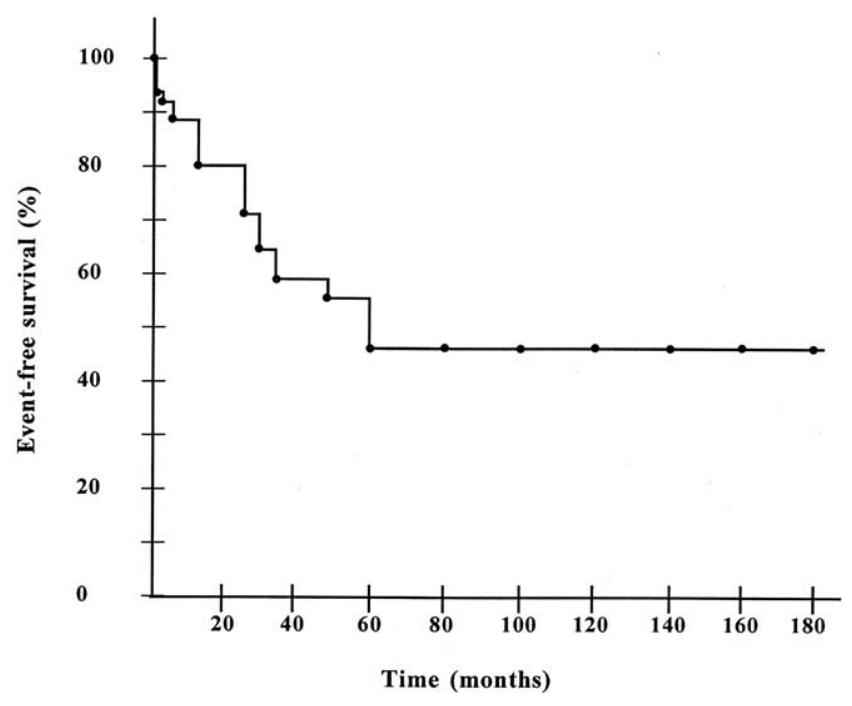

Figure 2. Event-free survival (Kaplan-Meier) in children after mitral valve repair.

\begin{tabular}{|c|c|c|c|c|c|c|}
\hline Time interval (mo) & 0 & 12 & $>36$ & 60 & 120 & 180 \\
\hline Patients at risk & 272 & 195 & 95 & 67 & 25 & 15 \\
\hline Actuarial survival (\%) & 100 & 80.4 & 58.7 & 55.7 & 46.7 & 46.7 \\
\hline Standard error & 0 & 2.4 & 3.3 & 3.5 & 4.7 & 4.7 \\
\hline
\end{tabular}

heart size; (3) problems of long-term anticoagulation, thromboembolism, and bleeding; (4) rapid degeneration of the available bioprosthesis in the young population; (5) higher risk of endocarditis; and (6) suboptimal preservation of ventricular function and reduced long-term survival. ${ }^{5-8,16,17}$ Because of these problems, mitral valve repair is the procedure of choice for MR in the young. ${ }^{5-8,16-21}$

Repair is technically more difficult in this group of patients, and the failure rates are higher, with reoperation rates between $5 \%$ to $27 \%$ compared with the $8 \%$ to $10 \%$ rate in the adult population at 5 years of follow-up..$^{6-8,17-20}$ In one large series, it was found that the rate of repair was inversely related to the age of the patient: At maximum follow-up of 52 months, the reoperation rate in this series was $23.6 \%$ in patients 20 years of age or younger compared with $9.6 \%$ in older patients. ${ }^{5}$ In our early experience, the reoperation rate was $5.98 \%{ }^{8}$ in this study, it was $6 \%$ at a longer follow-up. Rheumatic etiology, mixed lesions, thickened cusps, and younger age have been associated with an early rate of valve failure. ${ }^{4-6,16,18-20}$ In an earlier study of more than 800 patients of all age groups undergoing mitral valve repair at our institution, we found that only younger age, left ventricular dysfunction, mixed lesions, and the need for cuspal thinning were independent risk factors for development of significant MR $;^{5}$ however, in the present study, only left ventricular dysfunction and mixed lesions were independent risk factors in the younger population.

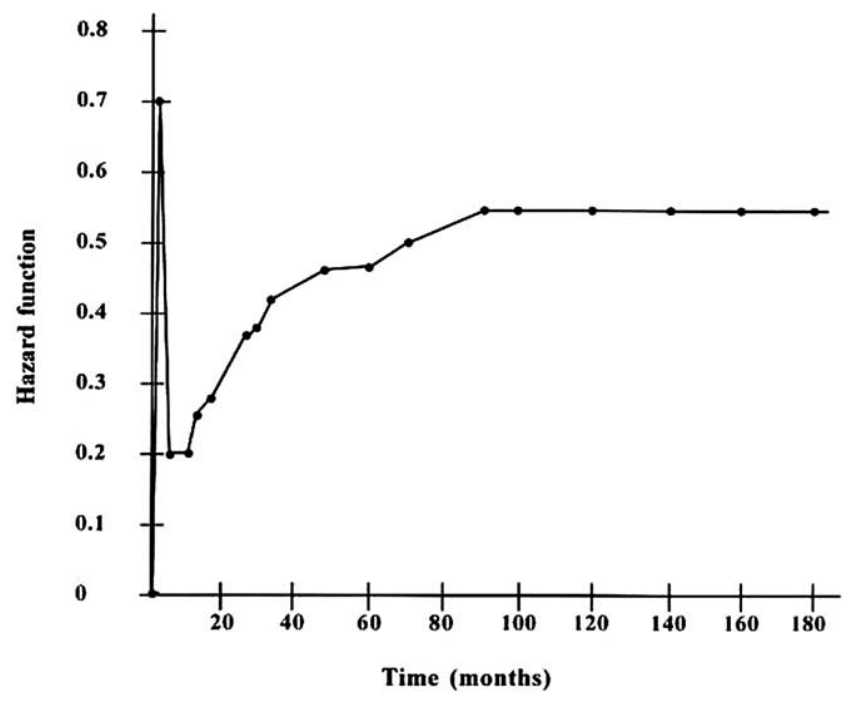

Figure 3. Instantaneous risk (hazard function) for development of significant mitral regurgitation across time after mitral valve repair.

The instantaneous hazard for developing significant MR was higher (Figure 3 ) in the immediate postoperative phase and remained constant for the first 18 months of follow-up. This plateau was followed by a gradual rise up to 6 years, followed by intermittent peaks and a plateau after 10 years of follow-up. This finding correlates with our previous observation that the early peak could be due to suboptimal repair..$^{5}$ The later peaks may be due to recurrence and progression of rheumatic activity.

The results of MVR in children are inferior to those of mitral valve repair. In a report of 90 children undergoing MVR, the in-hospital mortality was 19\% with 6 thromboembolic events and 9 bleeding complications on follow-up. ${ }^{7}$ In a large study of the long-term results of mitral valve repair in 254 young patients with chronic rheumatic MR, the operative mortality was $2.6 \%$, late mortality was $15 \%$, and the reoperation rate was $27 \%$ at 5 years of follow-up. ${ }^{4}$ In contrast, we observed an operative mortality of $2.2 \%$ and a late mortality of only $2.6 \%$. Mitral valve repair is thus clearly superior to MVR. A large number of these young patients enjoy a carefree childhood and adolescence and have children before returning for reoperation. The reoperation rates in patients undergoing initial repair or replacement are similar, which favors repair as an option.

\section{Conclusion}

Mitral valve repair in children with rheumatic heart disease is feasible and provides acceptable long-term results.

We thank Dr Rajvir Singh, PhD (Biostatistics), for statistical analysis. 


\section{References}

1. Loop FD. Long-term results of mitral valve repair. Semin Thorac Cardiovasc Surg. 1989;1:203-10.

2. Antunes MJ, Magalhaes MP, Colsen PR, Kinsley RH. Valvuloplasty for rheumatic mitral valve disease. A surgical challenge. J Thorac Cardiovasc Surg. 1987;94:44-56.

3. Duran CM, Gometza B, Saad E. Valve repair in rheumatic mitral disease: an unsolved problem. J Card Surg. 1994; 9 (2 suppl):282-5.

4. Skoularigis J, Sinovich V, Joubert G, Sareli P. Evaluation of the long-term results of mitral valve repair in 254 young patients with rheumatic mitral regurgitation. Circulation. 1994;90(5 pt 2):II167-74.

5. Choudhary SK, Talwar S, Dubey B, Chopra A, Saxena A, Kumar AS. Mitral valve repair in a predominantly rheumatic population. Longterm results. Tex Heart Inst J. 2001;28:8-15.

6. Duran CG, Revuelta JM, Gaite L, Alonso C, Fleitas MG. Stability of mitral reconstructive surgery at 10-12 years for predominantly rheumatic valvular disease. Circulation. 1988;78(3 pt 2):I91-6.

7. Erez E, Kanter KR, Isom E, Williams WH, Tam VK. Mitral valve replacement in children. J Heart Valve Dis. 2003;12:25-9.

8. Kumar AS, Rao PN, Saxena A. Results of mitral valve reconstruction in children with rheumatic heart disease. Ann Thorac Surg. 1995;60: 1044-7.

9. Helmcke F, Nanda NC, Hsiung MC, Soto B, Adey CK, Goyal RG, et al. Color Doppler assessment of mitral regurgitation with orthogonal planes. Circulation. 1987;75:175-83.

10. Grossman W. Profiles in valvular heart disease. In: Baim DS, Grossman W, editors. Cardiac catheterization, angiography, and intervention. 5th ed. Baltimore: Willams \& Wilkins;1996, p.742-4.

11. Kumar AS, Kumar RV, Shrivastava S, Venugopal P, Sood AK, Gopinath N. Mitral valve reconstruction: early results of a modified cooley technique. Tex Heart Inst J. 1992;19:107-11.
12. Kumar AS, Rao PN. Restoration of pliability to the mitral leaflets during reconstruction. J Heart Valve Dis. 1995;4:251-3.

13. Kumar AS, Bhan A, Kumar RV, Shrivastava S, Sood AK, Gopinath N. Cusp-level chordal shortening for rheumatic mitral regurgitation: early results. Tex Heart Inst J. 1992;19:47-50.

14. Edmunds LH, Clark Re, Cohn LH, Grunkemeier GL, Miller DC, Weisel RD. Guidelines for reporting morbidity and mortality after cardiac valvular operations. J Thorac Cardiovasc Surg. 1996;112:708-11.

15. Chockalingam A, Prabhakar D, Dorairajan S, Priya C, Gnanavelu G, Venkatesan S. Rheumatic heart disease: occurrence, patterns, and clinical correlates in children aged less than five years. $J$ Heart Valve Dis. 2004;13:11-4.

16. Enriquez-Sarano M, Schaff HV, Orszulak TA, Tajik AJ, Bailey KR, Frye RL. Valve repair improves the outcome of surgery for mitral regurgitation: a multivariate analysis. Circulation. 1995;91: 1022-8.

17. Galloway AC, Colvin SB, Baumann FG, Grossi EA, Ribakove GH, Harty S, et al. A comparison of mitral valve reconstruction with mitral valve replacement: intermediate-term results. Ann Thorac Surg. 1989; 47:655-62.

18. Aharon AS, Laks H, Drinkwater DC, Chugh R, Gates RN, Grant PW, et al. Early and late results of mitral valve repair in children. J Thorac Cardiovasc Surg. 1994;107:1262-70.

19. Duran CM, Gometza B, De Vol EB. Valve repair in rheumatic mitral disease. Circulation. 1991;84(5 suppl):III125-32.

20. Prabhakar G, Kumar N, Gometza B, Galal O, Al-Halees Z, Duran CM. Triple-valve operation in the young rheumatic patient. Ann Thorac Surg. 1993;55:1492-6.

21. Duran CM, Gometza B, Saad E. Valve repair in rheumatic mitral disease: an unsolved problem. J Card Surg. 1994;9(2 suppl):282-5. 